\title{
Defining bioidentical hormones for menopause-related symptoms
}

\author{
Anne Marie WHELAN, Tannis M. JURGENS, Melanie TRINACTY. \\ Received (first version): 7-Dec-2010 Accepted: 24-Jan-2011
}

\begin{abstract}
${ }^{*}$
In the last decade, the use of bioidentical hormones $(\mathrm{BHs})$ to treat menopause-related symptoms has become increasingly popular. However, the many different definitions of $\mathrm{BHs}$ have led to a great deal of confusion often making it difficult for health care providers to discuss this area with patients. Objective: The purpose of this paper was to produce a concise definition of bioidentical hormones, based on a review of the literature. Methods: Searches, using systematic review methodology, were conducted from inception to June 2010 in PubMed, EMBASE, IPA, The Journal of International Compounding and the Internet to identify definitions of bioidentical hormones. There were no restrictions on type, date or language of publication. Included papers/website included those that contained a definition of BHs. Definitions were extracted, similarities and differences summarized, and these were then examined to produce a concise definition.

Results: Sixty-three definitions were found. Based on the analysis of similarities and differences, the following definition, comprised of three components (term being defined; category to which term belongs; distinctive characteristics of term) was produced: "Bioidentical hormones are chemical substances that are identical in molecular structure to human hormones."

Conclusions: This definition clearly and concisely explains the meaning of $\mathrm{BH}$ s which should lead to a common understanding of the term and limit confusion among health care providers, the general public and the scientific community.
\end{abstract}

Keywords: Hormone Replacement Therapy. Menopause. Dissent and Disputes.

\section{DEFINIENDO HORMONAS BIOIDÉNTICAS PARA SÍNTOMAS ASOCIADOS A LA MENOPAUSIA}

\section{RESUMEN}

En la década pasada, se ha vuelto popular el uso de hormonas bioidenticas (HB) para tratar los síntomas asociados a la menopausia. Sin embargo, las muchas definiciones de HB han llevado a una gran confusión haciendo, a menudo, difícil para los profesionales de la salud discutir esto con los pacientes.

Objetivo: El propósito de este artículo es producir una definición concisa de hormonas bioidenticas, basándose en una revisión de la literatura.

Métodos: Para identificar definiciones de $\mathrm{HB}$, sSe realizaron búsquedas en PubMed, EMBASE, IPA, Journal of International Compounding e Internet desde su inicio hasta junio de 2010, utilizando metodología de revisión sistemática. No hubo restricciones en cuanto al tipo, fecha o idioma de las publicaciones. Los artículos/páginas web incluidas comprendían aquellas que contenían una definición de HB. Se extrajeron las definiciones, y se resumieron las similitudes y diferencias, y después se examinaron éstas para producir una definición concisa.

Resultados: Se encontraron 63 definiciones.

Basándose en el análisis de similitudes y diferencias, se produjo la siguiente definición, que comprendía tres componentes (término bien definido; categoría a la que pertenece el término; características distintivas del término): "Hormonas bioidenticas son substancias químicas que son idénticas en estructura molecular a las hormonas humanas".

Conclusiones: Esta definición explica clara y resumidamente el significado de HB lo que debería llevar a un entendimiento común del término y reducir la confusión entre los profesionales de la salud, el público en general y la comunidad científica.

Palabras clave: Tratamiento hormonal sustitutivo. Menopausia. Diferencias y Disputas.

\section{INTRODUCTION}

Anne Marie WHELAN. PharmD, Associate Professor. College of Pharmacy, Dalhousie University; Pharmacy Consultant, Department of Family Medicine, Dalhousie University. Halifax, Nova Scotia (Canada).

Tannis M. JURGENS. PhD, Associate Professor. College of Pharmacy, Dalhousie University. Halifax, Nova Scotia (Canada).

Melanie TRINACTY. BSc, BScPharm (Undergraduate Student). College of Pharmacy, Dalhousie University. Halifax, Nova Scotia (Canada).
In the last decade, the use of bioidentical hormones (BHs) have become popular in the management of menopause-related symptoms, in part, due to popular press coverage from books such as that published in 2006 by Suzanne Somers titled: Ageless: The Naked Truth About Bioidentical Hormones. ${ }^{1}$ In spite of their widespread use, there 
is actually a great deal of confusion as to the exact meaning of the term "bioidentical hormone $(\mathrm{BH})$ ". According to Rosenthal, the original use of the term "bioidentical hormones" can be traced to a book on natural hormone replacement authored by Wright and Morganthaler in $1997 .^{2}$ Initially, the term was used to describe the difference between patentable and unpatentable hormones. ${ }^{2}$ The meaning of $\mathrm{BH}$ has evolved and there are now a variety of definitions available in the lay press as well as in the health and scientific literature including those from various health organizations that have policy or position statements published on the topic of $\mathrm{BHs}$ or bioidentical hormone therapy. ${ }^{3-5}$ For example, one paper $^{6}$ defines BHs as "customized preparations that contain hormones that are identical to those endogenously produced in the human body" while another author refers to $\mathrm{BHs}$ as "hormones that are specific to perform the functions our bodies require". 7 The lack of a consistent definition for $\mathrm{BHs}$ has led to some misperceptions, such as the common belief that BHs are "natural" and therefore safer than hormones traditionally used for menopause -related symptoms. ${ }^{8}$ There is also the belief that $\mathrm{BHs}$ are only available in the widely promoted preparations that are custom compounded for specific patients; many do not realize that $\mathrm{BHs}$ are also available in commercial products. The variety of definitions and beliefs about the meaning of bioidentical hormones can make it challenging for a health care provider to answer a patient's questions about $\mathrm{BHs}$.

Therefore, the objectives of this project were to 1) examine the range of published definitions of bioidentical hormones and 2) summarize the results to synthesize a concise definition of $\mathrm{BHs}$.

\section{METHODS}

Literature searches and data extraction were conducted using systematic review methodology.

\section{Literature Search}

A systematic search of the literature was conducted (May to June 2010) using Pubmed, EMBASE, IPA and the International Journal of Pharmaceutical Compounding to identify articles that contained definitions of the term bioidentical hormones. The term 'bioidentical hormones' is not a MeSH, and therefore the following text word searches were performed in PubMed to identify relevant articles: "bioidentical hormone replacement therapy", "bioidentical hormone therapy", "bioidentical hormones review", "bio-identical hormones", and "bioidentical hormones". Similar text word searches were performed in the other databases and the International Journal of Pharmaceutical Compounding. There were no limits set for type, date or language of publication or species (human or animal). One reviewer screened the initial search results to remove duplicate articles. Remaining articles were then assessed by two reviewers to determine if they contained a definition of $\mathrm{BHs}$. Disagreements were resolved using a third investigator to reach consensus. Articles were excluded if they defined "bioidentical hormone therapy" or "bioidentical hormone replacement therapy". Definitions for 'natural hormones' were excluded unless the article specifically stated that the terms 'natural hormone' and 'bioidentical hormone' were synonymous.

\section{Internet Search}

Google was used, in June 2010, to conduct a search of the internet using the text words "what are bioidentical hormones". This search was not intended to be comprehensive but rather a scan of internet sites containing definitions of 'bioidentical hormones' that would be commonly encountered by the general public. Screening of websites was limited to the first 10 websites, based on research that indicated consumers typically look no further than the first 10 websites or the first page of search results. ${ }^{9,10}$ The same methodology that was used in identifying definitions in the literature was applied to those identified on the internet.

\section{Analysis}

Definitions from the literature and internet searches were extracted and compiled into tables. Definitions were examined for similarities and differences. Data extraction and examinations were performed independently by two investigators and then compared. In cases of disagreement, the third investigator was consulted and a consensus reached. Following consensus agreement, summaries of the similarities and differences from both the internet and literature searches were collated. A definition of bioidentical hormones that reflected the similarities among definitions was constructed. This was framed using the three components of a definition: 1) term being defined; 2 ) category the term belongs to; and 3) characteristics of the term that make it distinctive from others in its class. $^{11}$

\section{RESULTS}

The search of the databases and journal identified 279 articles, 101 of which were eliminated as duplicates (Figure 1). Of the remaining 178 articles, 55 contained definitions of 'bioidentical hormones' and were included in the analysis. ${ }^{2,3,5-7,12-61}$ The search of the internet resulted 181,000 hits and the first 10 websites were screened for definitions of 'bioidentical hormones' (Figure 2). Eight sites contained definitions of 'bioidentical hormones' and were included in the analysis. ${ }^{30,62-68}$

Similarities and differences among the definitions were summarized (Table 1). The most consistent similarity among the definitions was the use of the word 'identical'. However, what BHs were identical to and how BHs were 'identical' differed among definitions. For example, the terms endogenous or human were frequently used to describe what BHs were identical to. Words used in conjunction with how $\mathrm{BHs}$ were identical included: structurally, chemically, molecularly, biologically, and biochemically.

Several additional differences were identified among the definitions. There were several definitions that stated the source of $\mathrm{BHs}$, and 
identified the source as either plant-derived, from animals, through de novo synthetic production, laboratory-fabricated, or not human in origin. Some definitions mentioned specific hormones that were $\mathrm{BH}$, such as estrogen, progesterone, estrone, estriol, testosterone, dehydrepiandrosterone, estradiol, thyroxine, cortisol, and 17 beta estradiol, while others used general terms to refer to hormones (e.g., steroids, estrogens, and compounds). The degree to which $\mathrm{BHs}$ were identical varied between definitions, with some using the word "identical", while others used words such as: similar, exact, same, matches, and precisely. Several definitions mentioned ${ }^{30}$ that $\mathrm{BHs}$ were 'natural' or were "a more natural approach to hormone therapy" but there was no consensus on using the term 'natural' in conjunction with BHs. There were a small number of definitions that mentioned either safety or function of BHs. Some definitions stated that $\mathrm{BHs}$ were safer than conventional hormones and other definitions indicated that $\mathrm{BHs}$ acted to produce the same physiologic response in the body as endogenous hormones. Finally, several definitions mentioned that $\mathrm{BHs}$ were specific for individual patients or were customized preparations.

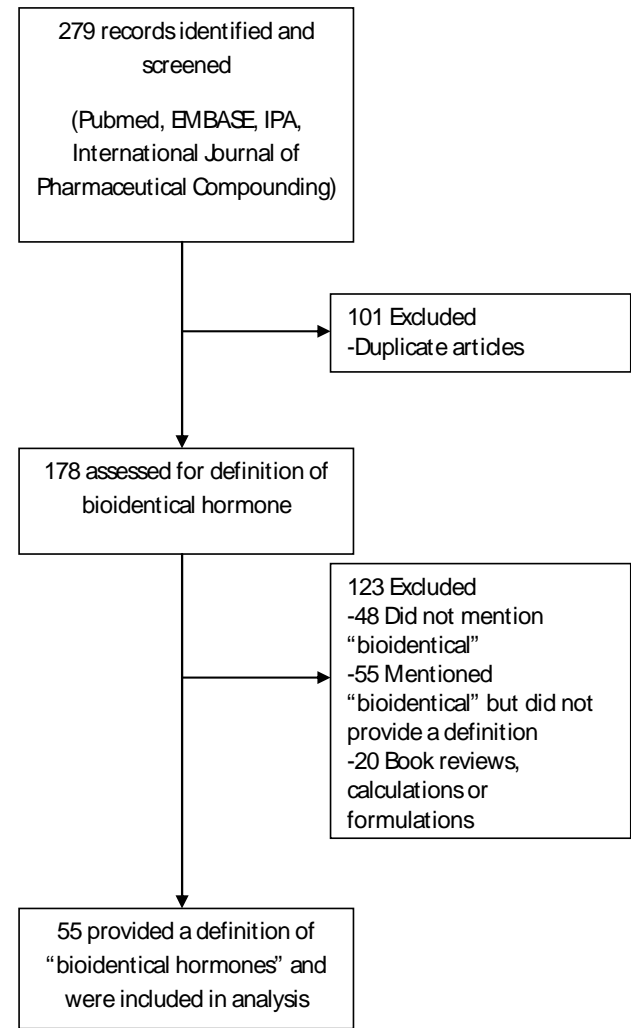

Figure 1: Results of the Database and Literature Search

Subsequent to this review of the similarities and differences, the following definition was produced to reflect the similarities among the definitions: bioidentical hormones are chemical substances that are identical in molecular structure to human hormones.

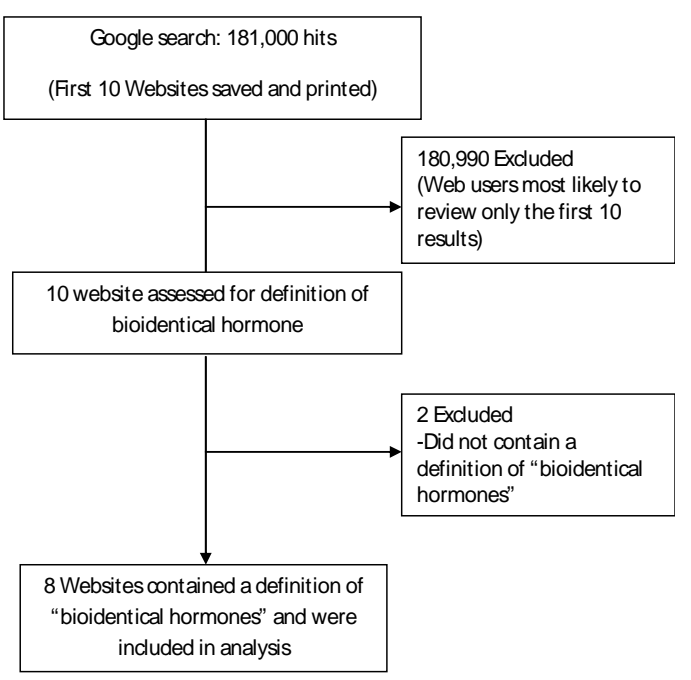

Figure 2: Results of the Internet Search

\section{DISCUSSION}

This review identified over 60 definitions for 'bioidentical hormones', both from the literature and websites. In clarifying the meaning of $\mathrm{BHs}$, we elected to frame the definition using the three components of a definition. ${ }^{11}$ The first component is the term being identified - that is 'bioidentical hormones'. For the second component, we needed to state the category to which the term belongs. Hormones, in general, are referred to ${ }^{69}$ as 'chemical substances', and therefore we elected to describe $\mathrm{BH}$ s using the same terminology.

To address the third component of a definition, we needed to express the characteristics of the term that make it distinctive from others in its class. In doing this, several factors were considered. Firstly, as previously stated, there was a consensus of use of the word 'identical' among the definitions for BHs. Although some identified definitions used words such as 'similar', 'same', 'exact' and "precisely" to describe the degree of likeness to human hormones, the word 'identical' was used in our definition as this was the word used by the majority of definitions.

Secondly, 'endogenous' or 'human' were most often used to describe what $\mathrm{BH}$ were identical to. The word 'endogenous' refers to something that is produced within an organism and is not necessarily specific to humans. ${ }^{70}$ As $\mathrm{BHs}$ are, in the context of women's health, a term specific to humans, we elected to describe $\mathrm{BHs}$ as being identical to 'human hormones' and not 'endogenous hormones'.

Thirdly, we needed to describe exactly how $\mathrm{BHs}$ were identical to human hormones. Terms commonly used in definitions to describe how $\mathrm{BHs}$ were identical to human hormones included structurally, chemically, molecularly, biologically, and biochemically. The term 'molecular structure' was selected from the 5 terms as being the most descriptive because it refers to the specific arrangement of the atoms of a compound. ${ }^{71}$ The use of the term 'molecular structure' in the definition therefore means that the structure of the $\mathrm{BH}$ is an 


\begin{tabular}{|c|c|}
\hline Similarities & Differences \\
\hline \multirow{8}{*}{$\begin{array}{l}\text { Use of term 'Identical' - either alone or in combination } \\
\text { with other words -'Identical structure', 'Identical to } \\
\text { human hormones', 'Identical to endogenous hormones' }\end{array}$} & $\begin{array}{l}\text { Origin of hormone - human, women, human ovary, ovary, } \\
\text { women's ovaries }\end{array}$ \\
\hline & $\begin{array}{l}\text { Description of 'identical' } \quad-\quad \text { 'structurally', 'chemically', } \\
\text { 'molecularly', 'biologically', 'biochemically' (or variations of these } \\
\text { terms) }\end{array}$ \\
\hline & $\begin{array}{l}\text { Source of hormone- plant derived, animals, through de novo } \\
\text { synthetic production, laboratory-fabricated, not human in origin }\end{array}$ \\
\hline & $\begin{array}{l}\text { Type of Hormones } \\
\text {-General - steroid, estrogens, compounds } \\
\text {-Specific - estrogen, progesterone, estrone, estriol, } \\
\text { testosterone, dehydroepiandrosterone, estradiol, thyroxine, } \\
\text { cortisol, } 17 \text {-beta estradiol }\end{array}$ \\
\hline & $\begin{array}{l}\text { Degree of 'identical' - replicate, matches, similar, precise } \\
\text { duplicates, exact, exact mimics, same, precisely }\end{array}$ \\
\hline & $\begin{array}{l}\text { Natural - a more natural approach, these products are natural, } \\
\text { sometimes referred to as 'natural' hormones }\end{array}$ \\
\hline & $\begin{array}{l}\text { Safety/Function - safer than more conventional pharmaceutical } \\
\text { hormones, exert same physiologic response as endogenously } \\
\text { produced hormones in the body }\end{array}$ \\
\hline & $\begin{array}{l}\text { Population/Dosage }- \text { individual } \\
\text { preparations }\end{array}$ \\
\hline
\end{tabular}

exact copy of the human hormone not only in chemical make-up but also in special arrangement of the structure. Neither the term biological nor biochemical was used to explain identical, because these terms refer more to the action of the hormone in the body, rather than structure. ${ }^{27}$

Using this approach we produced a clear, precise definition for $\mathrm{BHs}$ that reflected the similarities among the identified definitions. Although similar definitions were identified in our search $30,38,44,48,54$, none of these appeared to be framed as concisely as ours using the three components that comprise a definition.

Several concepts and terms were not included in the definition as they appeared to be descriptors intended to aid in understanding the term but were not part of a concise, clear definition. For example, many definitions indicated that $\mathrm{BHs}$ are plantderived. However, a hormone does not have to be plant-derived to be bioidentical. ${ }^{20}$ The definition of $\mathrm{BHs}$ is an explanation of what a hormone must be to be considered $\mathrm{BH}$ and not a description of where they came from, or could come from. Therefore the source of the hormone was not included in our definition.

Several definitions in the literature included a list of specific hormones such as estradiol, progesterone or testosterone. We considered these to be examples of $\mathrm{BHs}$ rather than a part of the definition.

The word 'natural' was not included in our definition although it was mentioned several times. It was not included because 'natural' can be interpreted in several different ways. For example, it can be used to indicate that the hormone came from a natural source, such as a plant. Although this may be true, plant-sourced hormones must undergo a chemical conversion before they are actually identical in structure to the hormones the human body produces. ${ }^{19}$ It is controversial, then, whether the final hormone can still be considered "natural" regardless of its source. Other people may associate the term 'natural' with 'safety'. ${ }^{21}$ In fact, it was reported that the terms 'natural', 'nonsynthetic' and 'bioidentical' were used as part of public relations strategies to increase sales. ${ }^{43}$ In a survey assessing women's beliefs about natural hormone replacement therapy only $10.8 \%$ of women believed the term 'natural hormone' meant bioidentical to human hormones. ${ }^{72}$ However, this survey did not ask the question in reverse, "what do you believe the term 'bioidentical hormone' means?". 72

There were definitions identified that included references to safety, efficacy, target populations or dosage forms. None of these aspects were included in our definition of $\mathrm{BHs}$. The safety and function of these products has not been fully elucidated and is part of the description of $\mathrm{BHs}$ rather than the definition. ${ }^{4}$ Bioidentical hormones are available in a variety of dosage forms and therapy is often individualized to specific patients, both of which provide further description of $\mathrm{BHs}$ but are not part of the definition. ${ }^{3}$

\section{Strengths and Limitations}

This appears to be the first paper to systematically review the literature for definitions of the term 'bioidentical hormones' and to produce a definition based on similarities and differences. There were significant challenges associated with searching for definitions of $\mathrm{BHs}$, as well as producing a definition of the term. The literature search was conducted using text word searches as there are no terms associated with $\mathrm{BHs}$ that are available as $\mathrm{MeSH}$ or Emtree terms. Although a text word search was clearly the only option for searching this topic, it is known that text word searching is less precise than searching using MeSH or Emtree terms. Therefore, in addition to relevant results, additional records were generated that were not necessarily pertinent to the topic of $\mathrm{BHs}$ and required elimination from analysis. ${ }^{73,74}$ Another challenge of our search was the discrepancy regarding the spelling of the term 
'bioidentical'. In some references it was spelled 'bioidentical' while in others the term was hyphenated as 'bio-identical'. To account for this, all searches were performed with and without the hyphen.

The internet search was performed using the search engine Google ${ }^{\mathrm{TM}}$, the most popular internet search engine according to Nielsen ratings from September 2009. ${ }^{75}$ The search term used in the internet search was <what are bioidentical hormones>, in an attempt to imitate a search by a typical consumer. This allowed us to identify the types of definitions that were easily accessible and likely to be obtained by consumers interested in the topic of bioidentical hormones.

\section{CONCLUSIONS}

Assessment of over 60 definitions of the term 'bioidentical hormone' revealed that there was a lack of consensus throughout the literature and on the internet as to a standard definition for the term. After a complete analysis of similarities and differences for all identified definitions the following definition was proposed: bioidentical hormones are chemical substances that are identical in molecular structure to human hormones". It is hoped that a clear, concise definition will lead to a common understanding of the term and limit confusion among health care providers, the general public and the scientific community.

\section{ACKNOWLEDGEMENTS}

The authors would like to thank Elizabeth Foy, Professional Information Officer at the Dalhousie College of Pharmacy, for providing searching support for this project.

The project was funded by the Dalhousie Pharmacy Endowment Fund.

\section{CONFLICT OF INTEREST}

No conflicts of interest to declare.

\section{References}

1. Somers S. Ageless: The Naked Truth About Bioidentical Hormones. 1st ed. New York: Crown Publishing Group; 2006.

2. Rosenthal MS. Ethical problems with bioidentical hormone therapy. Int J Impot Res. 2008;20(1):45-52.

3. Estrogen and progestogen use in postmenopausal women: 2010 position statement of the North American menopause society. Menopause. 2010;17(2):242-255

4. The Endocrine Society Position Statement: Bioidentical Hormones [Internet]. Endocrine Society [cited 2010 June 22]. Available from: http://www.endosociety.org/advocacy/policy/upload/BH_Position_Statement_final_10_25_06_w_Header.pdf.

5. ACOG Committee Opinion \#322: Compounded bioidentical hormones. Obstet Gynecol. 2005;106(5 Pt 1):1139-1140.

6. Shepherd JE, Bopp J. Pharmacy-based care for perimenopausal and postmenopausal women. J Am Pharm Assoc. (Wash) 2002;42(5):700,711-712.

7. Allen LV. Interview on HRT: Christiane Northrup. Int J Pharm Compd. 1998;2(1):12-17.

8. Boothby LA, Doering PL, Kipersztok S. Bioidentical hormone therapy: a review. Menopause. 2004;11(3):356-367.

9. Peterson G, Aslani P, Williams KA. How do consumers search for and appraise information on medicines on the Internet? A qualitative study using focus groups. J Med Internet Res. 2003;5(4):33.

10. Eysenbach G, Kohler C. How do consumers search for and appraise health information on the world wide web? Qualitative study using focus groups, usability tests, and in-depth interviews. BMJ. 2002;324(7337):573-577.

11. Pepper M, Driscoll D. Writing Definitions [Internet]. Purdue Online Writing Lab [cited 2010 Jul 9]. Available from: http://owl.english.purdue.edu/owl/resource/622/01/.

12. Well E. Bioidentical hormones. Adv Nurse Pract. 2009;17(9):37-41.

13. Chervenak J. Bioidentical hormones for maturing women. Maturitas. 2009;64(2):86-89.

14. Holtorf $\mathrm{K}$. The bioidentical hormone debate: are bioidentical hormones (estradiol, estriol, and progesterone) safer or more efficacious than commonly used synthetic versions in hormone replacement therapy? Postgrad Med. 2009;121(1):73-85

15. Sites CK. Bioidentical hormones for menopausal therapy. Womens Health (Lond). 2008;4(2):163-171.

16. Schaefer T. Patient information: bioidentical hormone therapy. Could it be right for you? Adv Nurse Pract. 2008;16(9):27.

17. Hansen K. Bioidentical hormones: panacea for menopausal hormonal therapy or bio-beware? S D Med. 2008;61(7):244-245.

18. Boothby LA, Doering PL. Bioidentical hormone therapy: a panacea that lacks supportive evidence. Curr Opin Obstet Gynecol. 2008;20(4):400-407.

19. Patsner B. Pharmacy compounding of bioidentical hormone replacement therapy (BHRT): a proposed new approach to justify FDA regulation of these prescription drugs. Food Drug Law J. 2008;63(2):459-491.

20. Cirigliano M. Bioidentical hormone therapy: a review of the evidence. J Womens Health. (Larchmt) 2007;16(5):600-631.

21. Fugh-Berman A, Bythrow J. Bioidentical hormones for menopausal hormone therapy: variation on a theme. J Gen Intern Med. 2007;22(7):1030-1034.

22. Moskowitz D. A comprehensive review of the safety and efficacy of bioidentical hormones for the management of menopause and related health risks. Altern Med Rev. 2006;11(3):208-223.

23. Campbell S. Bioidentical hormones. Achieving the perfect fit. Adv Nurse Pract. 2006;14(2):25,29,30. 
24. MacLennan AH, Sturdee DW. The 'bioidentical/bioequivalent' hormone scam. Climacteric. 2006;9(1):1-3.

25. McKee J, Warber SL. Integrative therapies for menopause. South Med J. 2005;98(3):319-326.

26. Weisenbach TM. Bioidentical hormone therapy for menopausal and perimenopausal patients. Adv Nurse Pract. 2004;12(8):77-80.

27. Romero M. Bioidentical hormone replacement therapy. Customizing care for perimenopausal and menopausal women. Adv Nurse Pract. 2002;10(11):47-52.

28. Walker CR. Bioidentical hormone replacement therapy. A natural option for perimenopause and beyond. Adv Nurse Pract. 2001;9(5):39,42,45.

29. Collins D. Bioidentical hormone therapy. An overview of benefits and prescribing guidance. Adv Nurse Pract. 2008;16(5):41-46, 68.

30. What are bioidentical hormones? Natural. Bioidentical. Compounded. Confusion about these terms is only adding to the confusion over hormone therapy. Harv Womens Health Watch. 2006;13(12):1-3.

31. Mahmud K. Natural hormone therapy for menopause. Gynecol Endocrinol. 2010;26(2):81-85.

32. Burrell BA. The replacement of the replacement in menopause: hormone therapy, controversies, truth and risk. Nurs Inq. 2009;16(3):212-222.

33. Kuehn BM. FDA warns claims for pharmacy-made "bio-identical" hormones are misleading. JAMA. 2008;299(5):512.

34. Ribot C, Tremollieres F. Hormone replacement therapy in postmenopausal women: all the treatments are not the same. Gynecol Obstet Fertil. 2007;35(5):388-397.

35. Curcio JJ, Wollner DA, Schmidt JW, Kim LS. Is Bio-Identical Hormone Replacement Therapy Safer than Traditional Hormone Replacement Therapy?: A Critical Appraisal of Cardiovascular Risks in Menopausal Women. Treat Endocrinol. 2006;5(6):367-374.

36. Wright JV. Bio-identical steroid hormone replacement: selected observations from 23 years of clinical and laboratory practice. Ann N Y Acad Sci. 2005;1057:506-524.

37. Francisco L. Is bio-identical hormone therapy fact or fairy tale? Nurse Pract. 2003;28(7 Pt 1):39,44.

38. Watt PJ, Hughes RB, Rettew LB, Adams R. A holistic programmatic approach to natural hormone replacement. Fam Community Health. 2003;26(1):53-63.

39. Panay N, Fenton A. Bioidentical hormones: What is all the hype about. Climacteric. 2010;13(1):1-3.

40. Menopause medicine: The bottom line on bioidentical hormone therapy. Geriatrics. 2008;63(9):28-29.

41. Collins JJ, Ahlgrimm M. Hormone therapy it's time for a second opinion. Int J Pharm Compd. 2008;12(2):122-127.

42. Hays B. Solving the puzzle of hormone replacement. Altern Ther Health Med. 2007;13(3):50-57.

43. Altman AM. Bioidentical hormones: What's fact and what's fable? Sex Reprod Menopause. 2007;5(1):13-16.

44. Benda W. Bioidentical hormones set the current political stage. Integr Med. 2006;5(5):58-61.

45. Schmidt JW, Wollner D, Curcio J, Riedlinger J, Kim LS. Hormone replacement therapy in menopausal women: Past problems and future possibilities. Gynecol Endocrinol. 2006;22(10):564-577.

46. Taylor M. "Bioidentical" estrogens: Hope or hype? Sex Reprod Menopause. 2005;3(2):68-71.

47. Bioidentical hormones. The bottom line on compounded hormones. Mayo Clin Womens Healthsource. 2005;9(9):1-2.

48. Koumis T, Nathan JP, Rosenberg JM. What is bioidentical HRT and is there evidence to support its use? Drug Topics. $2005 ; 149(9)$.

49. DeGarmo R. Defending bioidentical hormones [4]. Drug Topics. 2005;149(6).

50. Page K, Brownie S, Wohlmuth H. Natural management options for menopause. Integr Med. 2005;4(1):20-28.

51. Hu FS, ReedKane D, Draugalis JR. Patient satisfaction with pharmacist intervention and consultation in hormone replacement therapy: An update. Int J Pharm Compd. 2006;10(3):187-192.

52. Vigesaa KA, Downhour NP, Chui, Cappellini L, McCallian DJ. Efficacy and tolerability of compounded bioidentical hormone replacement therapy. Int J Pharm Compd. 2004;8(4):313-319.

53. Wepfer ST. Science behind bioidentical hormone replacement therapy. Part 1. Indian Journal of Natural Products. $2001 ; 5(6): 462-464$.

54. ReedKane D. Natural hormone replacement therapy: what it is and what consumers really want. Indian Journal of Natural Products. 2001;5(5):332-333.

55. Lorentzen J. Hormone Replacement Therapy: Part 1 - The Evolution of Hormone Treatment. Int J Pharm Compd. $2001 ; 5(5): 336-338$.

56. Vail J. "Natural" or "bioidentical" hormone replacement: What makes the difference? An interview with Christopher B. Cutter, MD. Int J Pharm Compd. 2003;7(1):24-26.

57. Price DL. Common acronyms used by health professionals who prescribe or prepare hormone replacement therapy. Int J Pharm Compd. 2007;11(4):288-291.

58. Allen LV. The politics of hormone replacement therapy. Int J Pharm Compd. 2007;11(4):278-281

59. Stephenson K, Jones W, Stephenson DMM. The role of drug promotion in the prescription of hormone replacement therapy in the United States. Int J Pharm Compd. 2006;10(3):175-184.

60. Reed-Kane D. Patient handout: Hormone replacement therapy. Int J Pharm Compd. 2003;7(5):339.

61. Goodrum J. Estriol: Women's choice vs. a manufacturer's greed. Int J Pharm Compd. 2008;12(4):286-292.

62. Definition:bioidentical hormones [Internet]. Google [cited 2010 June 23]. Available from: http://www.google.ca/search?hl=en\&defl=en\&q=define:bioidentical+hormones\&sa=X\&ei=pOAMTKWbCcGBIAfns9SVDg \&ved $=0$ CBsQkAE. 
63. Pettle A. Bio-Identicals [Internet]. Ruth Pettle Wellness Centre [cited 2010 June 23]. Available from: http://www.drpettle.com/bio-identical-hormones.htm.

64. Bioidentical hormone replacement therapy [Internet]. Wikipedia [cited 2010 June 23]. Available from: http://en.wikipedia.org/wiki/Bioidentical_hormone_replacement_therapy.

65. Kaye M. Bioidentical hormones: Are they safe? - The hormone conundrum [Internet]. More magazine [cited 2010 June 23]. Available from: http://www.more.ca/body-and-mind/health/bioidentical-hormones-are-they-safe/a/17.

66. Bioidentical Therapy [Internet]. Westcoast Womens Clinic [cited 2010 June 23]. Available from: http://www.westcoastwomensclinic.com/bioidentical_therapy.html.

67. The Alternative that Isn't: Bioidentical Hormones [Internet]. Science-Based Pharmacy [cited 2010 June 23]. Available from: http://sciencebasedpharmacy.wordpress.com/2009/03/13/bioidentical-hormone-replacement/.

68. Pick M. Bioidentical hormones come of age - Hormone Replacement Therapy [Internet]. Women to Women [cited 2010 June 23]. Available from: http://www.womentowomen.com/bioidentical-hrt/bioidenticalhormones.aspx.

69. Hormone [Internet]. Dorland's Illustrated Medical Dictionary [cited $2010 \mathrm{Jul} 21$ ]. Available from: http://www.credoreference.com/entry/ehsdorland/hormone.

70. Endogenous [Internet]. Dorland's Illustrated Medical Dictionary [cited 2010 Jul 21]. Available from: http://www.credoreference.com/entry/ehsdorland/endogenous.

71. Barkhouse S, Boyd R, Burford N, Doucette A, Grundy K, Guy R. Concepts in Chemistry: Structure and Reactivity. 1st ed. Halifax, Nova Scotia: Dalhousie Printing Centre; 2006.

72. Adams C, Cannell S. Women's beliefs about "natural" hormones and natural hormone replacement therapy. Menopause. 2001;8(6):433-440.

73. Chang AA, Heskett KM, Davidson TM. Searching the literature using medical subject headings versus text word with PubMed. Laryngoscope. 2006;116(2):336-340.

74. Jenuwine ES, Floyd JA. Comparison of Medical Subject Headings and text-word searches in MEDLINE to retrieve studies on sleep in healthy individuals. J Med Libr Assoc. 2004;92(3):349-353.

75. Top Search Providers for August 2009 [Internet]. Search Engine Watch (SEW) [cited 2010 June 24]. Available from: http://searchenginewatch.com/3634991. 